\title{
Effectiveness of maintenance treatments for nonsmall cell lung cancer
}

\author{
This article was published in the following Dove Press journal: \\ Lung Cancer:Targets and Therapy \\ 2I July 20I I \\ Number of times this article has been viewed
}

\author{
Matthew J Eadens \\ Steven I Robinson \\ Katharine AR Price \\ Division of Medical Oncology, Mayo \\ Clinic, Rochester, MN, USA
}

Correspondence: Katharine AR Price

Division of Medical Oncology,

Mayo Clinic, 200 First Street SW,

Rochester, MN 55905, USA

Tel +I 5072844849

Fax + I 507284 I803

Email price.katharine@mayo.edu

\begin{abstract}
Maintenance therapy for advanced nonsmall cell lung cancer has shown some clinical benefit for patients by improving progression-free survival and, to a lesser extent, overall survival. Two main strategies exist for maintenance therapy, ie, continuation and switch maintenance. Continuation maintenance involves the continued use of one of the induction drugs beyond 4-6 cycles of initial treatment. Switch maintenance utilizes a third agent initiated after first-line chemotherapy. Both cytotoxic agents and targeted agents have been studied. Switch maintenance therapy with pemetrexed in nonsquamous tumors and erlotinib appear to show the most clear clinical benefit. Continuation maintenance with bevacizumab has shown improvement in progression-free survival. Data concerning the role of cetuximab for maintenance is conflicting. Toxicity, quality of life, and cost are important confounding issues that need to be considered. Several ongoing Phase III trials are investigating strategies to improve on the current agents as well as testing promising new therapies.
\end{abstract}

Keywords: lung cancer, chemotherapy, maintenance therapy, targeted therapy

\section{Introduction}

Lung cancer is the most lethal cancer, accounting for 157,300 of the 569,490 predicted cases of cancer death in the US for $2010 .{ }^{1}$ Nonsmall cell lung cancer (NSCLC) accounts for the majority of these cases. Despite modest advances in the treatment of NSCLC with chemotherapy and targeted agents, the majority of patients present with distant disease (about 55\%) and have a dismal 5-year overall survival rate of $4 \%{ }^{1}$ Thus, there is a pressing need to improve outcomes for patients with advanced NSCLC. The current standard first-line treatment for patients with newly diagnosed advanced NSCLC and a good performance status is cytotoxic chemotherapy with a platinum doublet. ${ }^{2}$ Unfortunately, the median overall survival remains less than one year even in patients who receive standard first-line chemotherapy. ${ }^{3}$ This review seeks to explore the efficacy and practicality of maintenance therapy, a strategy that has gained prominence in recent years. Maintenance therapy is considered to be the use of chemotherapy in the absence of disease progression following the accepted 4-6 cycles of first-line treatment with a platinum-containing regimen. ${ }^{4}$ In this paper, we review the published Phase III evidence for maintenance therapy in NSCLC and will discuss competing issues of toxicity and cost-effectiveness.

\section{Efficacy of maintenance therapy for NSCLC}

The efficacy of maintenance therapy for advanced NSCLC is a controversial topic that has recently been reviewed..$^{5-7}$ The primary benefit of maintenance therapy appears to be 
the extension of progression-free survival, as demonstrated in a recent meta-analysis analyzing 13 randomized control trials and 3027 patients. The authors found that by extending chemotherapy, the progression-free survival was statistically improved (hazard ratio [HR]: $0.75 ; 95 \%$ confidence interval [CI]: $0.69-0.81 ; P<0.00001)$. The overall survival was also improved but the magnitude of the benefit was much less (HR: 0.92; 95\% CI: 0.86-0.99; $P=0.03$ ). ${ }^{8}$ This review explores the two major approaches to maintenance therapy for advanced NSCLC, ie, continuation and switch maintenance, and examine the major trials that have led to the acceptance of this approach to patient care. We will also discuss issues related to toxicity, quality of life, and cost.

\section{Continuation maintenance therapy}

Continuation maintenance therapy is defined as the continued administration of one of the first-line agents after the standard 4-6 cycles of induction chemotherapy in the absence of disease progression. ${ }^{4}$ Several different cytotoxic agents as well as targeted agents have been studied in this setting (Tables 1 and 2, respectively). Gemcitabine and paclitaxel are two chemotherapeutic agents that have been systematically investigated in randomized Phase III trials. Pemetrexed has also shown promise as continuation maintenance therapy in a Phase II trial in combination with bevacizumab. ${ }^{9}$ In the Phase II study reported by Patel et al, chemotherapy-naïve patients with stage IIIB or IV nonsquamous NSCLC with stable or responsive disease following six cycles of pemetrexed $500 \mathrm{mg} / \mathrm{m}^{2}$, carboplatin area under the curve (AUC) 6 , and bevacizumab $15 \mathrm{mg} / \mathrm{kg}$ given every 3 weeks were continued on maintenance pemetrexed and bevacizumab until disease progression or unacceptable toxicity. Fifty patients were enrolled, $60 \%$ were able to participate in the continuation phase, and the overall response rate was 55\% in 49 assessable patients. Median progression-free survival and overall survival were 7.8 (95\% CI: 5.2-11.5 months) and 14.1 months (95\% CI: 10.8-19.6 months), respectively, with acceptable toxicity. ${ }^{9}$ Randomized Phase III data for pemetrexed continuation maintenance is presently an area of active investigation but has not yet been reported.

\section{Gemcitabine}

The use of gemcitabine for continuation maintenance therapy for advanced NSCLC has been studied in three randomized controlled trials, ${ }^{10-12}$ two of which have demonstrated an improvement in progression-free survival on the order of 1-2 months. ${ }^{10,11}$ No trials to date have shown a survival benefit for the continuation of gemcitabine beyond its use in a first-line platinum doublet. Brodowicz et $\mathrm{al}^{10}$ investigated the use of gemcitabine maintenance therapy of $1250 \mathrm{mg} / \mathrm{m}^{2}$ on days 1 and 8 of a 21-day cycle in patients with stage IIIB/IV NSCLC who had no worse than stable disease following an initial regimen of gemcitabine $1250 \mathrm{mg} / \mathrm{m}^{2}$ on days 1 and 8 of a 21-day cycle and cisplatin $80 \mathrm{mg} / \mathrm{m}^{2}$ on day 1 . Seventy-three percent $(n=257)$ of the initial 352 patients had at least stable disease after induction therapy; 206 patients were ultimately randomized in a 2:1 fashion to gemcitabine maintenance $(n=138)$ or best supportive care $(n=68)$. Time to progression (primary endpoint of the study) was significantly longer in the maintenance arm for both the entire study period (6.6 vs 5.0 months, $P<0.001)$ and maintenance period (3.6 vs 2.0 months, $P<0.001$ ). Overall survival showed a nonsignificant increase for the entire study period (13.0 vs 11.0 months, $P=0.195$ ) and for the maintenance period (10.2 vs 8.1 months, $P=0.195$ ), and a similar proportion of patients in each arm proceeded on to second-line therapy after progression $(56.6 \% \mathrm{vs} 57.1 \%$ for the maintenance and best supportive care arms, respectively).

Table I Survival outcomes in Phase III trials of continuation maintenance with chemotherapy

\begin{tabular}{|c|c|c|c|c|c|}
\hline Author & Patients (n) & Induction regimen & Maintenance regimen & $\begin{array}{l}\text { PFS } \\
\text { (months) }\end{array}$ & $\begin{array}{l}\text { OS } \\
\text { (months) }\end{array}$ \\
\hline Brodowicz et al $^{10}$ & 352 & Cisplatin and gemcitabine & Gemcitabine vs BSC & $\begin{array}{l}6.6 \text { vs } 5.0^{\mathrm{a}} \\
(P<0.00 \mathrm{I}) \\
3.6 \text { vs } 2.0^{\mathrm{b}} \\
(P<0.00 \mathrm{I})\end{array}$ & $\begin{array}{l}\text { I3.0 vs II.0 } \\
(P=0.195)\end{array}$ \\
\hline Perol et al ${ }^{11, c}$ & 834 & Cisplatin and gemcitabine & Gemcitabine vs placebo ${ }^{d}$ & $\begin{array}{l}3.8 \text { vs } 1.9 \\
(P<0.000 \mathrm{I})\end{array}$ & $\begin{array}{l}\text { I2.I vs } 10.7 \\
\text { (NS) }\end{array}$ \\
\hline Belani et al $\left.\right|^{12, c}$ & 519 & Carboplatin and gemcitabine & Gemcitabine vs BSC & $\begin{array}{l}3.9 \text { vs } 3.8 \\
(P=N S)\end{array}$ & $\begin{array}{l}8.0 \text { vs } 9.3 \\
(P=0.84)\end{array}$ \\
\hline Belani et $\mathrm{al}^{13}$ & 401 & Carboplatin and paclitaxel & Paclitaxel vs observation & $\begin{array}{l}38 \text { vs } 29 \\
\text { weeks }^{\mathrm{a}, \mathrm{e}}\end{array}$ & $\begin{array}{l}75 \text { vs } 60 \\
\text { weeks }^{e}\end{array}$ \\
\hline
\end{tabular}

Notes: aTPP during entire study period; ' TTP during maintenance period; cabstract presented at 2010 American Society of Oncology annual meeting; ${ }^{d}$ data for erlotinib vs placebo is presented in Table 4; ${ }^{\mathrm{e}}$ value not reported.

Abbreviations: BSC, best supportive care; OS, overall survival; PFS, progression-free survival; TTP, time to progression; NS, not statistically significant. 
Table 2 Survival outcomes in Phase III trials of continuation maintenance with targeted agents

\begin{tabular}{|c|c|c|c|c|c|}
\hline Author & $\begin{array}{l}\text { Patients } \\
\text { (n) }\end{array}$ & $\begin{array}{l}\text { Induction } \\
\text { regimen }\end{array}$ & $\begin{array}{l}\text { Maintenance } \\
\text { regimen }\end{array}$ & PFS (months) & OS (months) \\
\hline $\begin{array}{l}\text { Pirker et al } \\
(\text { FLEX) }\end{array}$ & 1125 & $\begin{array}{l}\text { Cisplatin, vinorelbine } \pm \\
\text { cetuximab }\end{array}$ & $\begin{array}{l}\text { Cetuximab vs } \\
\text { observation }\end{array}$ & $\begin{array}{l}4.8 \text { vs } 4.8 \\
(P=0.39)\end{array}$ & $\begin{array}{l}\text { II.3 vs I0.I } \\
(P=0.044)\end{array}$ \\
\hline $\begin{array}{l}\text { Lynch et al } \\
(\text { BMS099) }\end{array}$ & 676 & $\begin{array}{l}\text { Carboplatin, paclitaxel } \\
\text { or docetaxel } \pm \text { cetuximab }\end{array}$ & $\begin{array}{l}\text { Cetuximab vs } \\
\text { observation }\end{array}$ & $\begin{array}{l}4.4 \text { vs } 4.2 \\
(P=0.236)\end{array}$ & $\begin{array}{l}9.6 \text { vs } 8.3 \\
(P=0.169)\end{array}$ \\
\hline $\begin{array}{l}\text { Herbst et al } \\
\text { (TRIBUTE) }^{18}\end{array}$ & 1079 & $\begin{array}{l}\text { Carboplatin, paclitaxel } \pm \\
\text { erlotinib }\end{array}$ & $\begin{array}{l}\text { Erlotinib vs } \\
\text { placebo }\end{array}$ & $\begin{array}{l}5.1 \text { vs } 4.9 \\
(P=0.36)^{\mathrm{a}}\end{array}$ & $\begin{array}{l}10.6 \text { vs } 10.5 \\
(P=0.95)\end{array}$ \\
\hline $\begin{array}{l}\text { Gatzemeier et al } \\
\text { (TALENT) }^{19}\end{array}$ & 1172 & $\begin{array}{l}\text { Cisplatin, gemcitabine } \pm \\
\text { erlotinib }\end{array}$ & $\begin{array}{l}\text { Erlotinib vs } \\
\text { placebo }\end{array}$ & $\begin{array}{l}23.7 \text { vs } 24.6 \\
\text { weeks }^{\mathrm{a}} \\
(P=0.74)\end{array}$ & $\begin{array}{l}43 \text { vs } 44.1 \text { weeks } \\
(P=0.49)\end{array}$ \\
\hline $\begin{array}{l}\text { Giaccone et al } \\
(\text { INTACT I })^{20}\end{array}$ & 1093 & $\begin{array}{l}\text { Cisplatin, gemcitabine } \pm \\
\text { gefitinib ( } 500 \text { or } 250 \mathrm{mg} / \text { day) }\end{array}$ & $\begin{array}{l}\text { Gefitinib } 500 \mathrm{mg} \text { vs } \\
\text { gefitinib } 250 \mathrm{mg} \text { vs placebo }\end{array}$ & $\begin{array}{l}5.5 \text { vs } 5.8 \text { vs } \\
6.0^{\mathrm{a}}(P=0.76)\end{array}$ & $\begin{array}{l}9.9 \text { vs } 9.9 \text { vs } 10.9 \\
(P=0.45)\end{array}$ \\
\hline $\begin{array}{l}\text { Herbst et al } \\
(\text { INTACT 2) }\end{array}$ & 1037 & $\begin{array}{l}\text { Carboplatin, paclitaxel } \pm \\
\text { gefitinib ( } 500 \text { or } 250 \mathrm{mg} / \text { day) }\end{array}$ & $\begin{array}{l}\text { Gefitinib } 500 \mathrm{mg} / \text { day vs } \\
\text { gefitinib } 250 \mathrm{mg} / \text { day vs placebo }\end{array}$ & $\begin{array}{l}4.6 \text { vs } 5.3 \text { vs } \\
5.0^{\mathrm{a}}(P=0.562)\end{array}$ & $\begin{array}{l}8.7 \text { vs } 9.8 \text { vs } 9.9 \\
(P=0.64)\end{array}$ \\
\hline $\begin{array}{l}\text { Sandler et al } \\
(\text { ECOG 4599 })^{22}\end{array}$ & 878 & $\begin{array}{l}\text { Carboplatin, paclitaxel } \pm \\
\text { bevacizumab }\end{array}$ & Bevacizumab vs BSC & $\begin{array}{l}6.2 \text { vs } 4.5 \\
(P<0.00 I)\end{array}$ & $\begin{array}{l}\text { I2.3 vs } 10.3 \\
(P=0.003)\end{array}$ \\
\hline $\begin{array}{l}\text { Reck et al } \\
(\text { AVAiL) })^{23,24}\end{array}$ & 1043 & $\begin{array}{l}\text { Cisplatin/gemcitabine }+ \\
\text { bevacizumab } 7.5 \mathrm{mg} / \mathrm{kg} \text { or } \\
\text { bevacizumab } 15 \mathrm{mg} / \mathrm{kg} \text { or placebo }\end{array}$ & $\begin{array}{l}\text { Bevacizumab } 7.5 \mathrm{mg} / \mathrm{kg} \text { vs } \\
\text { bevacizumab } 15 \mathrm{mg} / \mathrm{kg} \text { vs } \\
\text { placebo }\end{array}$ & $\begin{array}{l}\text { HRbev7.5 }=0.75 \\
(P=0.0003) \\
\text { HRbev15 } 150.85 \\
(P=0.0456)\end{array}$ & $\begin{array}{l}\text { I3.6 }(P=0.42) \text { vs } \\
\text { I3.4 }(P=0.76 \mid) \text { vs } \\
\text { I3.| }\end{array}$ \\
\hline
\end{tabular}

Abbreviations: HRbev7.5, hazard ratio for bevacizumab $7.5 \mathrm{mg} / \mathrm{kg}$ arm; HRbev 15 , hazard ratio for bevacizumab $15 \mathrm{mg} / \mathrm{kg}$ arm; OS, overall survival; PFS, progression-free survival.

The second Phase III trial to demonstrate improvement in progression-free survival with gemcitabine continuation therapy was reported in abstract form by Perol et $\mathrm{al}^{11}$ at the 2010 annual meeting of the American Society of Clinical Oncology. This study randomized nonprogressing patients with advanced NSCLC to one of three arms after initial treatment with cisplatin and gemcitabine - gemcitabine maintenance $1250 \mathrm{mg} / \mathrm{m}^{2}$ on days 1 and 8 of a 21-day cycle, erlotinib maintenance $150 \mathrm{mg} /$ day, or observation. Progression-free survival was improved from 1.9 months in the observation arm to 3.8 months in the gemcitabine arm (HR: $0.55,95 \%$ CI: $0.43-0.70 ; P<0.0001)$ but median overall survival was not significantly improved. The investigators mandated the use of pemetrexed for progressive disease, which was received by $55 \%$ of patients in the gemcitabine arm and $72 \%$ in the observation arm. Grade 3-4 treatment-related adverse events were $27 \%$ in the gemcitabine group vs $2 \%$ in the observation group.

The third Phase III study to investigate gemcitabine as continuation maintenance therapy, also presented at the 2010 annual meeting of the American Society of Clinical Oncology, showed no improvement in either progressionfree survival or overall survival. ${ }^{12}$ It was limited by slow accrual, failing to reach the projected 238 target events over 6 years. Furthermore, $25 \%$ of the patients had a performance status of 2 or greater. ${ }^{6,12}$ In total, 519 patients with advanced NSCLC were enrolled and treated with gemcitabine $1000 \mathrm{mg} / \mathrm{m}^{2}$ on days 1 and 8 and carboplatin AUC 5 every 3 weeks for four cycles. Two hundred and fifty-five patients (49\%) did not have disease progression and were subsequently randomized to maintenance gemcitabine plus best supportive care $(\mathrm{n}=128)$ vs best supportive care alone $(n=127)$. Results showed no benefit for maintenance therapy in regard to overall survival (8.0 months for maintenance and 9.3 for best supportive care) or progression-free survival (3.9 months for maintenance and 3.8 months for best supportive care).

\section{Paclitaxel}

One Phase III trial reported by Belani et al provides some evidence of benefit for continuation maintenance therapy with paclitaxel. ${ }^{13}$ In this trial, 401 patients were randomized to one of three different first-line regimens combining paclitaxel and carboplatin. Patients with stable disease or better at 16 weeks were then randomized to paclitaxel $70 \mathrm{mg} / \mathrm{m}^{2}$ given three out of four weeks until progression $(n=65)$ vs observation $(n=65)$. Although this study was primarily designed to test the various first-line treatment arms and not for any significant maintenance differences, the maintenance arm did have improvements in both time to progression (38 vs 29 weeks) and overall survival (75 vs 60 weeks). In the maintenance arm, $45 \%$ of patients reported at least one grade 3 or 4 adverse event. Unfortunately due to sample size, a definitive statement on maintenance therapy could not be made by the investigators, and further investigation of paclitaxel as maintenance therapy is needed. 


\section{Targeted therapy against the epidermal growth factor receptor}

The epidermal growth factor receptor (EGFR) is one of a family of receptors involved in signal transduction pathways that are important in the proliferation and survival of cancer cells, and overexpression of EGFR has been demonstrated in NSCLC. ${ }^{14,15}$ Three targeted agents directed against the EGFR pathway have been investigated as maintenance therapy for advanced NSCLC, ie, the monoclonal antibody, cetuximab, and the tyrosine kinase inhibitors, erlotinib and gefitinib. Most of these noncytotoxic agents have been studied in combination with a platinum-doublet as first-line induction chemotherapy regimen followed by continuation maintenance of the targeted agent.

\section{Cetuximab}

The benefit of cetuximab as continuation maintenance therapy is unclear given the conflicting results of the two published Phase III trials. ${ }^{16,17}$ The FLEX trial enrolled patients with advanced NSCLC whose tumors expressed EGFR to first-line chemotherapy (cisplatin $80 \mathrm{mg} / \mathrm{m}^{2}$ on day 1 and vinorelbine $25 \mathrm{mg} / \mathrm{m}^{2}$ on days 1 and 8 ) plus cetuximab (400 mg/m $/ \mathrm{m}^{2}$ on day 1 and $250 \mathrm{mg} / \mathrm{m}^{2}$ weekly starting on day 8) or chemotherapy alone every 3 weeks for up to six cycles. ${ }^{16}$ After six cycles, the cetuximab-containing arm continued cetuximab until disease progression or excessive toxicity. Using an intention-to-treat analysis, 1125 patients were assigned to treatment (548 to chemotherapy plus cetuximab and 562 to chemotherapy alone). Two hundred and forty-one of the 548 patients $(44 \%)$ in the cetuximab arm were able to continue on with maintenance cetuximab. Progression-free survival was not improved, but the median overall survival in the cetuximab arm was 11.3 months compared with 10.1 months in the chemotherapy alone arm, a result that was statistically significant although marginal $(P=0.044)$. Response rate was also improved in the cetuximab arm ( $36 \%$ vs $29 \%$, $P=0.010$ ). Quality of life was reported as similar in the two arms, but the rate of return of the questionnaires was less than $15 \%$. Despite increased neutropenic fever ( $22 \%$ vs $15 \%$ ), acne-like rash $(10 \%$ vs $<1 \%)$, diarrhea $(5 \%$ vs $2 \%)$, and infusion-related reactions ( $4 \%$ vs $<1 \%$ ) for the cetuximab group vs chemotherapy alone, treatment-related death rates were similar ( $3 \%$ vs $2 \%$ ).

The BMS099 trial investigated the benefit of cetuximab with chemotherapy in an unselected population of 676 chemotherapy-naïve patients with advanced NSCLC. ${ }^{17}$ Patients were randomized to carboplatin AUC 6 with either paclitaxel $225 \mathrm{mg} / \mathrm{m}^{2}$ or docetaxel $75 \mathrm{mg} / \mathrm{m}^{2}$ given once every 3 weeks for up to six cycles with or without cetuximab $400 \mathrm{mg} / \mathrm{m}^{2}$ on day 1 , then $250 \mathrm{mg} / \mathrm{m}^{2}$ weekly. The primary endpoint of the study was progression-free survival; overall survival, quality of life, and safety were secondary endpoints. Like the FLEX trial, response rate was improved with the addition of cetuximab ( $25.7 \%$ vs $17.2 \%, P=0.0066)$ but there was no significant improvement in either progressionfree survival (4.4 months with cetuximab vs 4.2 months without, $P=0.236$ ) or overall survival (9.69 months with cetuximab vs 8.38 months without, $P=0.169$ ). Interestingly, subset analysis did suggest a more pronounced benefit on progression-free survival with the addition of cetuximab in patients with a performance status of 0 (HR: $0.73,95 \% \mathrm{CI}$ : 0.54-0.99), in patients treated with docetaxel (HR: $0.78,95 \%$ CI: $0.61-0.99$ ), and in patients with squamous cell histology (HR: $0.70,95 \%$ CI: $0.47-1.05$ ) but no increased benefit was found for overall survival.

\section{Erlotinib}

Two Phase III trials, ie, TRIBUTE and TALENT, ${ }^{18,19}$ have investigated the role of erlotinib as continuation maintenance therapy in an unselected population with advanced NSCLC. In the TRIBUTE trial, erlotinib $150 \mathrm{mg} /$ day or placebo was given with paclitaxel $200 \mathrm{mg} / \mathrm{m}^{2}$ on day 1 and carboplatin AUC 6 on day 1 once every 21 days for up to six cycles. The treatment plan for the TALENT trial was similar, except the chemotherapy consisted of gemcitabine $1250 \mathrm{mg} / \mathrm{m}^{2}$ on days 1 and 8 and cisplatin $80 \mathrm{mg} / \mathrm{m}^{2}$ on day 1 . In the TRIBUTE trial, 539 patients were randomized to the erlotinib arm and 540 to the placebo arm. Overall survival (the primary endpoint of the study) was not significantly improved in the erlotinib arm (10.6 vs 10.5 months, $P=0.95$ ). Response rate and time to progression were also not better in the study arm. However, on subset analysis, never-smokers were noted to have a survival advantage (22.5 vs 10.1 months; HR: 0.49, 95\% CI: $0.28-0.85 ; P=0.01)$. Similarly, TTP was greater in never-smokers ( 6 months vs 4.3 months; HR: $0.50,95 \% \mathrm{CI}$ : $0.31-0.80 ; P=0.002)$. Toxicities were similar between the groups, except for the anticipated increased rash and diarrhea in the erlotinib arm. ${ }^{18}$ The TALENT study randomized 586 patients to erlotinib plus chemotherapy with cisplatin and gemcitabine and 586 patients to placebo plus the same chemotherapy. As with the TRIBUTE trial, overall survival was not improved for the erlotinib arm (43 vs 44.1 weeks, $P=0.49$ ). Time to progression and response rate were not significantly different, but the duration of response was slightly longer in the erlotinib group (25.4 vs 23.9 weeks, $P=0.045)$. Never-smokers in the erlotinib arm also seemed to 
do better in this trial. ${ }^{19}$ Data on never-smokers was collected retrospectively. The median overall survival for smokers was 11.4 months with placebo and not reached with erlotinib. Median progression-free survival was similarly greater in never-smokers on erlotinib than placebo, at 7.9 vs 5.4 months, respectively $(P=0.02)$.

\section{Gefitinib}

Similar to erlotinib, gefitinib has been studied in combination with cytotoxic chemotherapy regimens and has shown similar disappointing results as continuation maintenance therapy. The INTACT 1 and 2 trials investigated the use of cytotoxic chemotherapy in combination with gefitinib. ${ }^{20,21}$ The platinum-based doublet for INTACT 1 was cisplatin $80 \mathrm{mg} / \mathrm{m}^{2}$ on day 1 and gemcitabine $1250 \mathrm{mg} / \mathrm{m}^{2}$ on days 1 and 8 given once every 21 days for up to six cycles. INTACT 2 used carboplatin AUC 6 on day 1 and paclitaxel $225 \mathrm{mg} / \mathrm{m}^{2}$ on day 1 once every 21 days for up to six cycles. In both trials, chemotherapy was combined with gefitinib $500 \mathrm{mg} /$ day, $250 \mathrm{mg} /$ day, or placebo, with continuation of this agent after the six cycles of induction chemotherapy until disease progression. The primary endpoint for both trials was overall survival. The results did not show a benefit of adding gefitinib to chemotherapy, and there was actually a nonsignificant trend towards better survival in the placebo groups. The secondary endpoints of progression-free survival, time to progression, and response rate also did not show a benefit.

\section{Antiangiogenic therapy: bevacizumab}

Bevacizumab, a monoclonal antibody to circulating vascular endothelial growth factor, is approved for use as first-line treatment along with carboplatin and paclitaxel in patients with nonsquamous NSCLC. ${ }^{22}$ Two Phase III trials have investigated the use of bevacizumab as continuation maintenance therapy, both showing improvement in progression-free survival. The ECOG 4599 study randomized 878 patients with recurrent or incurable nonsquamous NSCLC to receive either carboplatin $\mathrm{AUC}=6$, paclitaxel $200 \mathrm{mg} / \mathrm{m}^{2}$, and bevacizumab $15 \mathrm{mg} / \mathrm{kg}$ or carboplatin and paclitaxel alone. Treatment was given on day 1 every 3 weeks for up to six cycles. Of the 407 patients in the bevacizumab-containing arm, $215(53 \%)$ were able to proceed on to single-agent bevacizumab maintenance and 107 (50\%) of these patients received five or more cycles. Both progression-free survival (6.2 vs 4.5 months, $P<0.001$ ) and overall survival (12.3 vs 10.3 months, $P=0.003$ ) were improved in the bevacizumab arm. However, there were 15 treatment-related deaths in the bevacizumab arm compared with two in the chemotherapy arm $(P=0.001)$, mainly due to either hemorrhage or neutropenic fever.

The second Phase III trial investigating bevacizumab maintenance, the AVAiL trial, treated 1043 patients with advanced nonsquamous NSCLC with cisplatin $80 \mathrm{mg} / \mathrm{m}^{2}$ on day 1 and gemcitabine $1250 \mathrm{mg} / \mathrm{m}^{2}$ on days 1 and 8 with or without bevacizumab at either $7.5 \mathrm{mg} / \mathrm{kg}$ or $15 \mathrm{mg} / \mathrm{kg}$ once every 3 weeks for up to six cycles. Maintenance bevacizumab or placebo was continued in nonprogressing patients at the same doses. Progression-free survival was the primary endpoint with overall survival being a secondary endpoint. Of the randomized patients, 345 were assigned to the lower dose bevacizumab, 351 to the higher dose, and 347 to placebo, with $145(42 \%), 145(41 \%)$, and $128(37 \%)$ proceeding on to single agent maintenance, respectively. The bevacizumab arms had significantly better response rates (low-dose $34.1 \%$, high-dose $30.4 \%$ ) compared with placebo (20.1\%) as well as progression-free survival (HR: $0.75,95 \%$ CI: 0.64-0.87; $P=0.0003$ for bevacizumab $7.5 \mathrm{mg} / \mathrm{kg}$ and $\mathrm{HR}: 0.85,95 \%$ CI: $0.73-1.00 ; P=0.0456$ for bevacizumab $15 \mathrm{mg} / \mathrm{kg}),{ }^{23}$ but overall survival was not improved (13.1 months for placebo vs 13.6 for bevacizumab $7.5 \mathrm{mg} / \mathrm{kg}$ and 13.4 for bevacizumab $15 \mathrm{mg} / \mathrm{kg}){ }^{24}$

\section{Switch maintenance therapy}

Switch maintenance therapy involves the initiation of a cytotoxic or targeted agent that was not part of the first-line chemotherapy regimen, following the standard 4-6 cycles in the absence of disease progression. To date, there have been three randomized Phase III trials employing cytotoxic chemotherapy (Table 3) and five randomized Phase III trials utilizing targeted agents (Table 4) in the switch-maintenance approach that have been reported in the literature.

\section{Cytotoxic chemotherapeutic agents Vinorelbine}

The first Phase III trial to investigate switch maintenance therapy was reported by Westeel et al using vinorelbine after first-line platinum-based chemotherapy. ${ }^{25}$ The trial enrolled 573 chemotherapy-naïve patients with advanced NSCLC between 1994 and 2000 who received treatment with mitomycin, ifosfamide, and cisplatin. Patients were divided into stage IIIB and wet stage IIIB/stage IV. The former group received two cycles of mitomycin, ifosfamide, and cisplatin followed by thoracic irradiation and the latter received four cycles of chemotherapy. A total of 227 patients (39\%) responded to treatment and 181 patients were randomized to vinorelbine $25 \mathrm{mg} / \mathrm{m}^{2} /$ week for 6 months $(n=91)$ vs observation $(n=90)$. There was no 
Table 3 Survival outcomes in Phase III trials of switch maintenance with chemotherapy

\begin{tabular}{|c|c|c|c|c|c|}
\hline Author & Patients (n) & Induction regimen & Maintenance regimen & PFS (months) & OS (months) \\
\hline Westeel et $\mathrm{a}^{25}$ & 573 & $\begin{array}{l}\text { Mitomycin, } \\
\text { ifosfamide, } \\
\text { cisplatin }\end{array}$ & Vinorelbine vs observation & $\begin{array}{l}5.0 \text { vs } 3.0 \\
(P=0 . I I)\end{array}$ & $\begin{array}{l}\text { I } 2.3 \text { vs } I 2.3 \\
(P=0.65)\end{array}$ \\
\hline Fidias et $\mathrm{a}^{26}$ & 566 & $\begin{array}{l}\text { Carboplatin and } \\
\text { gemcitabine }\end{array}$ & Immediate vs delayed docetaxel & $\begin{array}{l}5.7 \text { vs } 2.7 \\
(P=0.000 I)\end{array}$ & $\begin{array}{l}\text { I } 2.3 \text { vs } 9.7 \\
(P=0.08)\end{array}$ \\
\hline Ciuleanu et $\mathrm{a}^{27}$ & $663^{a}$ & $\begin{array}{l}\text { Platinum-based doublet } \\
\text { (excluding pemetrexed) }\end{array}$ & Pemetrexed vs placebo & $\begin{array}{l}4.3 \text { vs } 2.6 \\
(P<0.000 \mathrm{I})\end{array}$ & $\begin{array}{l}\text { I3.4 vs } 10.6^{\mathrm{b}} \\
(P=0.012)\end{array}$ \\
\hline
\end{tabular}

Notes: aEnrollment occurred after induction chemotherapy (745 patients screened, 663 enrolled); ${ }^{b}$ difference in survival was noted in those with nonsquamous histology, 15.5 vs 10.3 months (hazards ratio $0.70,95 \%$ confidence interval $0.56-0.88, P=0.002$ ).

Abbreviations: OS, overall survival; PFS, progression-free survival.

difference in median overall survival (12.3 months for both groups, $P=0.65$ ) or progression-free survival ( 5 months for vinorelbine maintenance vs 3 months for observation, $P=0.11$ ). The toxicities were predominantly hematologic, with a greater propensity for cytopenias in the irradiated group. ${ }^{25}$

\section{Docetaxel}

In 2009, Fidias et al reported their findings for docetaxel switch maintenance in 566 patients with advanced NSCLC who were treated with four cycles of carboplatin and gemcitabine then randomized to immediate vs delayed docetaxel. ${ }^{26}$ Gemcitabine $1000 \mathrm{mg} / \mathrm{m}^{2}$ on days 1 and 8 and carboplatin AUC 5 on day 1 were given once every 21 days for four cycles. Patients with no evidence of disease progression were eligible for maintenance therapy with docetaxel. A total of 309 eligible patients were randomized to receive immediate docetaxel $75 \mathrm{mg} / \mathrm{m}^{2}$ on day 1 of 21-day cycles for up to six cycles vs delaying treatment with docetaxel until evidence of disease progression. The significant finding in this trial was the improvement in progression-free survival from 2.7 months to 5.7 months $(P=0.0001)$ favoring the immediate approach strategy. Whilst the median overall survival was prolonged for the immediate docetaxel group, it did not reach statistical significance (12.3 vs 9.7 months, $P=0.08$ ). Neutropenia, fatigue, and dyspnea were the predominant grade 3 and 4 adverse effects, with similar rates in both arms. This study included a quality of life questionnaire, with $85.8 \%$ and $71.9 \%$ compliance rates in the immediate and delayed arms, respectively, and no statistical difference noted $(P=0.76)$. Of note, there was a striking difference in the percentage of patients who actually received the prescribed treatment (94.8\% vs $62.8 \%$ in the immediate and delayed docetaxel groups, respectively). Progressive disease and patient decision were cited as the major causes for the decreased rate in the latter group. When analysis of the patients in the immediate and delayed docetaxel groups was limited to only patients who actually received the drug, the survival was 12.5 months for both groups. The authors concluded that earlier exposure to therapy while patients are at their most robust functional status would yield the most promising results.

\section{Pemetrexed}

The second Phase III trial published in 2009 investigating switch maintenance chemotherapy for advanced NSCLC

Table 4 Survival outcomes in Phase III trials of switch maintenance with targeted agents

\begin{tabular}{|c|c|c|c|c|c|}
\hline Authors & Patients (n) & Induction regimen & Switch regimen & PFS (months) & OS (months) \\
\hline $\begin{array}{l}\text { Takeda et al } \\
(\text { WJTOG0203) }\end{array}$ & 604 & $\begin{array}{l}\text { Platinum-based doublet } \\
(3-6 \text { cycles })^{\mathrm{a}}\end{array}$ & Gefitinib vs observation & $\begin{array}{l}4.6 \text { vs } 4.3 \\
(P<0.00 I)\end{array}$ & $\begin{array}{l}13.7 \text { vs } 12.9 \\
(P=0.11)^{b}\end{array}$ \\
\hline $\begin{array}{l}\text { Cappuzzo et al } \\
\text { (SATURN) }^{32}\end{array}$ & 1949 & Platinum-based doublet & Erlotinib vs placebo & $\begin{array}{l}\text { I } 2.3 \text { vs II.I weeks } \\
(P<0.000 \mid)\end{array}$ & $\begin{array}{l}I 2.0 \text { vs } I 1.0 \\
(P=0.0088)\end{array}$ \\
\hline $\begin{array}{l}\text { Perol et al } \\
(\text { IFCT-GFPC 0502) })^{11, c}\end{array}$ & 834 & Gemcitabine and cisplatin & Erlotinib vs observation & $\begin{array}{l}2.9 \text { vs } 1.9 \\
(P=0.002)^{\mathrm{d}}\end{array}$ & $\begin{array}{l}11.8 \text { vs } \\
10.7(\mathrm{NS})^{\mathrm{d}}\end{array}$ \\
\hline $\begin{array}{l}\text { Kabbinavar et al } \\
(\text { ATLAS) })^{33, c}\end{array}$ & $--^{e, f}$ & Platinum-based doublet & $\begin{array}{l}\text { Bevacizumab/erlotinib vs } \\
\text { bevacizumab/placebo }\end{array}$ & $\begin{array}{l}4.8 \text { vs } 3.7 \\
(P=0.0012)\end{array}$ & $\begin{array}{l}15.9 \text { vs } 13.9 \\
(P=0.26)\end{array}$ \\
\hline $\begin{array}{l}\text { Gafaar et al } \\
\text { (EORTC } 0802 \text { I-ILCP } 01 / 03)^{29, c}\end{array}$ & $-^{\mathrm{e}}$ & Platinum-based doublet & Gefitinib vs placebo & $\begin{array}{l}4.1 \text { vs } 2.9 \\
(P=0.0015)\end{array}$ & $\begin{array}{l}10.9 \text { vs } 9.4 \\
(P=0.2)\end{array}$ \\
\hline
\end{tabular}

Notes: ${ }^{a}$ Patients were randomized to six cycles of platinum doublet with observation vs three cycles of platinum doublet followed by gefitinib; ${ }^{b}$ subset analysis revealed greater OS in patients with adenocarcinomas $(P=0.03)$; ${ }^{c}$ presented as abstracts; ${ }^{d}$ values reported are for the erlotinib vs observation arms; ${ }^{e}$ patients were enrolled and randomized after induction chemotherapy; fotal number enrolled prior to induction therapy was not given. Ultimately 768 patients without disease progression were randomized to the maintenance arms.

Abbreviations: OS, overall survival; PFS, progression-free survival. 
involved the antifolate agent, pemetrexed, and ultimately led to approval by the US Food and Drug Administration for its use as maintenance therapy. Ciuleanu et al conducted a randomized, double-blind study that enrolled 754 patients from 20 countries with stage IIIB or IV disease. ${ }^{27}$ A total of 663 patients who received their initial therapy with a platinum-based regimen without evidence of disease progression were randomized in a $2: 1$ fashion to receive pemetrexed $\left(500 \mathrm{mg} / \mathrm{m}^{2}\right.$ on day 1$)$ vs placebo until disease progression. Treatment was administered in 21-day cycles. The 441 patients enrolled in the pemetrexed arm demonstrated superiority in the primary and secondary endpoints of progressionfree survival and overall survival, respectively, over the 221 patients who received placebo. The median progression-free survival for those patients who received pemetrexed was 4.3 months vs 2.6 months in the placebo arm (HR: 0.50, 95\% CI: 0.42-0.61, $P<0.0001)$. Similarly, the pemetrexed maintenance therapy conferred a 2.8-month difference in overall survival over placebo (13.4 vs 10.6 months; HR: $0.79,95 \%$ CI: $0.65-0.95 ; P=0.012$ ). Of note, patients with nonsquamous histology fared the best, with median survival times of 15.5 vs 10.3 months in the pemetrexed and placebo arms, respectively (HR: $0.70,95 \% \mathrm{CI}: 0.56-0.88 ; P=0.002$ ). In comparison, tumors of squamous histology had a median survival of 9.9 vs 10.8 months, respectively (HR: 1.07, 95\% CI: $0.77-1.50 ; P=0.678)$. Statistically significant grade 3 and 4 toxicities included fatigue in $5 \%(P=0.0001)$ and neutropenia in $3 \%(P=0.006)$ of patients who received pemetrexed. With regards to quality of life, pemetrexed significantly delayed the worsening of pain $(P=0.041)$ and hemoptysis $(P=0.038)$. The authors disclosed the data on postdiscontinuation treatment and notably only $67 \%$ of patients in the placebo arm received antineoplastic agents. Of these patients, only $18 \%$ received pemetrexed for secondline treatment, with the predominant choice being docetaxel (29\%). This last point has been a consistent criticism of this trial because conclusions could not be drawn about the timing of pemetrexed administration. However, the rate of secondline therapy in the delayed arm is very similar to other trials of this design, ${ }^{26}$ and supports the authors' conclusion that delay in therapy potentially increases the risk that patients may never receive additional therapy.

\section{Targeted agents}

As seen with continuation maintenance, targeted agents have also been studied in the switch maintenance setting. Targeted agents that have been studied include the EGFR tyrosine kinase inhibitors gefitinib and erlotinib and the monoclonal antibody bevacizumab. Table 4 summarizes the results of the major Phase III trials that employed these agents in a switch maintenance approach.

Similar to the previously discussed studies showing no benefit of continuation maintenance therapy with the EGFR tyrosine kinase inhibitors, gefitinib as switch maintenance therapy for NSCLC has not shown any survival benefit. Takeda et al reported the findings of the randomized Phase III gefitinib maintenance trial conducted by the West Japan Thoracic Oncology Group trial (WJTOG0203). ${ }^{28}$ A total of 604 patients with advanced NSCLC were enrolled and subsequently randomly assigned to receive either platinum-based doublet chemotherapy for up to six cycles ( $\operatorname{arm} A, n=301)$ or three cycles of the same regimen followed by gefitinib until evidence of disease progression ( $\operatorname{arm} B, n=302$ ). One patient was entered into both arms in error. Three patients in arm A and two patients in arm B did not receive chemotherapy. Thus 598 patients were analyzed. The primary endpoint of overall survival was not met, with median survival times of 12.9 and 13.7 months for the chemotherapy only and gefitinib maintenance arms, respectively (HR: 0.86, 95\% CI: 0.72-1.03; $P=0.11)$. Conversely, although the magnitude was slight, the secondary endpoint of progression-free survival was significantly in favor of the gefitinib arm, 4.6 months, as compared with the chemotherapy only group, 4.3 months (HR: $0.68,95 \%$ CI: $0.57-0.80 ; P<0.001$ ). An exploratory subset analysis was performed that found a significant prolongation of overall survival in patients with adenocarcinoma. As the study was planned prior to the recognition that tumors harboring EGFR mutations are more likely to respond to gefitinib, outcomes by EGFR mutation status were not available. There was no difference in the results of the disease-related symptom assessment questionnaires. ${ }^{28}$

Gaafar et al presented the results of the prematurely closed EORTC trial 08021 where patients with advanced NSCLC who showed no evidence of progression following four cycles of platinum-based induction chemotherapy were subsequently randomized to receive gefitinib $(n=86)$ vs placebo $(n=87) .{ }^{29}$ The results of this study were presented in poster discussion forums at the 2010 annual American Society of Clinical Oncology and European Society of Medical Oncology meetings. Unfortunately the trial closed enrollment after accruing only 173 of a targeted 598 patients. This was attributed to the published results of two Phase III placebo-controlled trials, SWOG S0023 $3^{30}$ and Iressa Survival Evaluation in Lung Cancer (ISEL), ${ }^{31}$ that showed no survival benefit with the use of gefitinib. There was a significant difference in the secondary endpoint of progression-free 
survival in favor of the experimental arm (4.1 vs 2.9 months; HR: $0.61,95 \%$ CI: $0.45-0.83 ; P=0.0015)$. However, there was no difference in overall survival (10.9 vs 9.4 months; HR: $0.83,95 \%$ CI: $0.60-1.15 ; P=0.2)$. Toxicities were similar to previous studies employing tyrosine kinase inhibitors.

The Sequential Tarceva in Unresectable NSCLC (SATURN) trial was a Phase III placebo-controlled study designed to test the efficacy of erlotinib as maintenance treatment. ${ }^{32}$ Unlike the aforementioned Japanese study of gefitinib, patients were additionally stratified by EGFR status. The study enrolled 1949 patients who received four cycles of platinum-based chemotherapy. The 889 patients (45\%) who had no evidence of progressive disease were then randomized in a 1:1 fashion to receive erlotinib $150 \mathrm{mg} /$ day $(\mathrm{n}=438)$ or placebo $(n=451)$ until disease progression or unacceptable toxicity. Erlotinib demonstrated superiority over placebo in the primary endpoint of progression-free survival (12.3 vs 11.1 weeks, respectively; HR: 0.71 , 95\% CI: 0.62-0.82; $P<0.0001)$. This finding was irrespective of EGFR status, smoking history, gender, or histology, including those with squamous cell tumors. The greatest difference, however, was observed in those with EGFR-activating mutations (HR: 0.10, 95\% CI: $0.04-0.25 ; P<0.0001)$. Overall survival similarly favored erlotinib over placebo (12.0 vs 11.0 months, respectively; HR: $0.81,95 \%$ CI: $0.70-0.95 ; P=0.0243)$. However the dramatic difference noted in progression-free survival in the EGFR mutation group did not manifest with as great a difference in overall survival (HR: $0.77,95 \%$ CI: 0.61-0.97; $P=0.0063)$ as expected in part attributed to the high degree of crossover (16 of 24 patients from the placebo arm). Not surprisingly the patients in the erlotinib arm experienced skin rash $(60 \%)$ and diarrhea $(18 \%)$. There was no difference in quality of life between the arms and erlotinib prolonged the time to pain and analgesic use. ${ }^{32}$

As previously discussed, the IFCT-GFPC 0502 study presented by Perol et al (see Tables 1 and 4) compared the role of treatment with chemotherapy or a targeted agent against observation following induction chemotherapy. ${ }^{11}$ A total of 464 patients without disease progression following four cycles of gemcitabine and cisplatin chemotherapy were subsequently randomized to receive gemcitabine $(n=149)$, erlotinib ( $n=153)$, or observation $(n=152)$. One of the strengths of this study was the designation of pemetrexed as the second-line therapy of choice for all arms, thus limiting the influence of varied salvage regimens on overall survival differences. Erlotinib significantly improved progression-free survival as compared with observation (2.9 vs 1.9 months; HR: $0.82,95 \%$ CI: $0.73-0.93 ; P=0.002)$. However, at the time of last analysis, it demonstrated no improvement in overall survival (11.8 vs 10.7 months; HR: 0.91, 95\% CI: $0.80-1.04 ; P=\mathrm{NS})$. The incidence of at least grade 3 toxicities with erlotinib was $14 \%$ and histology had no influence on the effect of erlotinib. ${ }^{11}$

Finally, the ATLAS study presented by Kabbinavar et al at the 2010 annual American Society of Clinical Oncology meeting reported the outcomes of 768 patients with stage IIIB/IV NSCLC who had no evidence of disease progression following four cycles of platinum-based doublet chemotherapy in conjunction with bevacizumab and who were randomized to receive bevacizumab $15 \mathrm{mg} / \mathrm{kg}$ every three weeks in combination with erlotinib $150 \mathrm{mg}$ /day vs bevacizumab and placebo. ${ }^{33}$ The study met its primary endpoint of progression-free survival in favor of the erlotinib arm (4.8 vs 3.7 months; HR: 0.72, 95\% CI: $0.59-0.88 ; P=0.0012$ ), and as a result was stopped early after the second planned interim analysis. However, at the time of the last analysis, although progression-free survival in the erlotinib arm was greater (15.9 vs 13.9 months), the difference in overall survival was not significant (HR: 0.90, 95\% CI: 0.74-1.09; $P=0.2686$ ). Skin rash and diarrhea were greater in the experimental arm as expected (10.4\% vs $0.5 \%$ and 9.3 vs $0.8 \%$, respectively). The authors did not report on quality of life outcomes. While this study showed the two drugs could be safely combined, it does not answer the question of whether or not bevacizumab should be continued following induction treatment.

\section{Toxicity and quality of life}

One important issue that needs to be considered when weighing the risks and benefits of maintenance therapy is toxicity. Although most of the studies report acceptable toxicity in the maintenance arm, many report some increase in grade 3 and 4 toxicities in patients receiving maintenance therapy. ${ }^{11,12,16,17,20-22,27}$ Maintenance therapy with the EGFR tyrosine kinase inhibitors appears to have the least toxicity, with the exception of the expected rash and diarrhea. When toxicity and quality of life were analyzed in the meta-analysis by Soon et al, adverse events were more common in the maintenance patients, and two of the seven trials that reported health-related quality of life outcomes did show trends toward a worse quality of life by extending chemotherapy. ${ }^{8}$ In addition, it was reported that patients on maintenance chemotherapy required more transfusions compared with best supportive care $(20 \%$ vs $6.3 \%, P=0.018) .{ }^{10}$ Even mild toxicity of maintenance therapy will compare unfavorably with the absence of treatment-related side effects associated with a chemotherapy holiday. 


\section{Cost-effectiveness of maintenance therapy}

Very few data are available on the cost-effectiveness of maintenance treatment, but certainly this issue needs to be considered in light of the rising costs in health care and the overall modest benefits of maintenance therapy. A recent analysis by Klein et al compared the cost-effectiveness of maintenance pemetrexed with observation as well as with maintenance erlotinib or bevacizumab. ${ }^{34}$ They employed a semi-Markov model that compared the impact of pemetrexed with other forms of maintenance therapy from a US payer perspective and concluded that maintenance pemetrexed was costeffective in patients with advanced nonsquamous NSCLC with an incremental cost per life-year gain of US \$122,371 over observation. In contrast, a cost-utility analysis performed in Switzerland of the addition of cetuximab to first-line chemotherapy for advanced NSCLC concluded that cetuximab could not be routinely recommended due to a high incremental cost-effectiveness ratio. ${ }^{35}$ Further analyses of cost compared with meaningful clinical benefit are needed.

\section{Discussion}

Maintenance therapy is one strategy that has shown promise in improving outcomes for patients with NSCLC.
Several cytotoxic and targeted therapies have demonstrated modest improvement, primarily in progression-free survival, but the degree of clinical benefit varies between agents and the clinical setting. Several Phase III trials are underway (Table 5) that will hopefully further define the role of maintenance therapy for specific patient subsets.

Several issues arise when interpreting the data on maintenance therapy and deciding on how to incorporate them into clinical practice. For example, it can be hard to ascertain fully the incremental benefit of the maintenance agent, such as in the trials of the targeted drugs for continuation maintenance. These agents (cetuximab, ${ }^{16,17}$ erlotinib, ${ }^{18,19}$ gefitinib, ${ }^{20,21}$ and bevacizumab ${ }^{22-24}$ ) were commonly included in the induction regimen for the experimental arm but not in the control arm. Additionally, the timing of therapy remains a key question when debating the risks and benefits of maintenance therapy. Delaying the use of second-line agents until clearcut disease progression spares the patient potential complications, toxicities, and increased health care contact. However, it is important to counsel patients that a significant proportion of people will not be well enough to receive second-line treatment.

Toxicities seem to be manageable in the maintenance setting based on reported adverse events although, as previously

Table 5 Ongoing Phase III maintenance therapy trials in nonsmall cell lung cancer

\begin{tabular}{|c|c|c|c|c|c|}
\hline Study & Sponsor & $\begin{array}{l}\text { Year opened } \\
\text { (target } \\
\text { enrolment) }\end{array}$ & Induction regimen & Maintenance arms & $\begin{array}{l}\text { Primary } \\
\text { endpoint }\end{array}$ \\
\hline NCT0I32895I & $\begin{array}{l}\text { Hoffmann-La } \\
\text { Roche }\end{array}$ & $\begin{array}{l}2011 \\
(n=610)\end{array}$ & Platinum doublet & $\begin{array}{l}\text { Immediate erlotinib vs placebo } \\
\text { with erlotinib at progression }\end{array}$ & OS \\
\hline $\begin{array}{l}\text { NCT00789373 } \\
\text { (PARAMOUNT trial) }\end{array}$ & Eli Lilly & $\begin{array}{l}2008 \\
(n=900)\end{array}$ & $\begin{array}{l}\text { Pemetrexed + } \\
\text { cisplatin }\end{array}$ & Pemetrexed vs placebo & PFS \\
\hline $\begin{array}{l}\text { NCT00820755 } \\
\text { (NEXT trial) }\end{array}$ & Merck & $\begin{array}{l}2009 \\
(n=1200)\end{array}$ & $\begin{array}{l}\text { Platinum-based doublet }+ \\
\text { cetuximab }\end{array}$ & $\begin{array}{l}\text { Cetuximab } 500 \mathrm{mg} / \mathrm{m}^{2} / \mathrm{q} 2 \mathrm{wk} \text { vs } \\
\text { cetuximab } 250 \mathrm{mg} / \mathrm{m}^{2} / \text { wkly }\end{array}$ & OS \\
\hline NCT00693992 & CALGB & $\begin{array}{l}2008 \\
(244)\end{array}$ & Platinum-based doublet & Sunitinib vs placebo & PFS \\
\hline NCT00948675 & Eli Lilly & $\begin{array}{l}2009 \\
(n=360)\end{array}$ & $\begin{array}{l}\text { (I) Pemetrexed + carboplatin vs } \\
\text { (2) carboplatin }+ \text { paclitaxel }+ \\
\text { bevacizumab }\end{array}$ & $\begin{array}{l}\text { (I) Continued pemetrexed vs } \\
\text { (2) continued bevacizumab }\end{array}$ & PFS \\
\hline $\begin{array}{l}\text { NCT0096I4I5 } \\
\text { (AVAPERLI) }\end{array}$ & $\begin{array}{l}\text { Hoffmann-La } \\
\text { Roche }\end{array}$ & $\begin{array}{l}2009 \\
(n=362)\end{array}$ & $\begin{array}{l}\text { Cisplatin }+ \text { pemetrexed }+ \\
\text { bevacizumab }\end{array}$ & $\begin{array}{l}\text { Bevacizumab vs bevacizumab + } \\
\text { pemetrexed }\end{array}$ & PFS \\
\hline NCT00762034 & Eli Lilly & $\begin{array}{l}2008 \\
(n=900)\end{array}$ & $\begin{array}{l}\text { Pemetrexed + carboplatin }+ \\
\text { bevacizumab vs paclitaxel }+ \\
\text { carboplatin + bevacizumab }\end{array}$ & $\begin{array}{l}\text { Continued pemetrexed }+ \\
\text { bevacizumab vs continued } \\
\text { bevacizumab }\end{array}$ & OS \\
\hline $\begin{array}{l}\text { NCT00676507 } \\
\text { (Lucanix vaccine therapy) }\end{array}$ & $\begin{array}{l}\text { NovaRX } \\
\text { Corporation }\end{array}$ & $\begin{array}{l}2008 \\
(n=700)\end{array}$ & Platinum-based doublet & Lucanix $^{\mathrm{TM}}$ vaccine vs placebo & OS \\
\hline NCTOI 208064 & EORTC & $\begin{array}{l}2010 \\
(n=600)\end{array}$ & First-line chemotherapy & Pazopanib vs placebo & OS \\
\hline NCTOI 107626 & ECOG & $\begin{array}{l}2010 \\
(n=1282)\end{array}$ & $\begin{array}{l}\text { Carboplatin }+ \text { paclitaxel }+ \\
\text { bevacizumab }\end{array}$ & $\begin{array}{l}\text { Pemetrexed vs bevacizumab vs } \\
\text { pemetrexed }+ \text { bevacizumab }\end{array}$ & OS \\
\hline
\end{tabular}

Abbreviations: OS, overall survival; PFS, progression-free survival; CALGB, Cancer and Leukemia Group B; EORTC, European Organisation for Research and Treatment of Cancer; ECOG, Eastern Cooperative Oncology Group. 
discussed, there are slight increases in grade 3 and 4 toxicities in many of the trials, and there may be an overall decrement in quality of life. ${ }^{8}$ None of the trials reported grade 1 and 2 toxicities which, although mild, can still have a negative impact on a patient's day-to-day life, particularly when one starts using more than one maintenance drug. ${ }^{33}$ One aspect of maintenance therapy that is not discussed is the intangible benefit of providing patients with time away from treatment. The cost of maintenance therapy is an important issue that needs further investigation, particularly in light of the current economic situation and the rising costs of health care. Issues of cost and toxicity underscore the importance of identifying subsets of patients likely to benefit from maintenance treatment instead of treating everyone in an unselected fashion.

Of the cytotoxic options, the strongest evidence is for switch maintenance therapy with pemetrexed in nonprogressing, nonsquamous histology patients. In current practice, many clinicians continue pemetrexed after its use in frontline treatment, presumably based on its benefits in switch maintenance trials and because pemetrexed is an attractive choice for first-line treatment given its favorable side effect profile. Unfortunately, we currently lack the Phase III data to support continuation maintenance with pemetrexed. The ongoing PARAMOUNT Phase III trial will hopefully provide the needed evidence to support what is now being commonly practiced (Table 5). Erlotinib also appears to be beneficial as switch maintenance ${ }^{11,31}$ but not in continuation maintenance or in combination with induction chemotherapy. ${ }^{18,19}$ However, given the strong evidence that the tyrosine kinase inhibitors are most effective for patients with EGFR-mutant NSCLC, ${ }^{36-40}$ it is difficult to recommend erlotinib maintenance to an unselected patient population. Docetaxel as switch maintenance also demonstrated a benefit but only in terms of progression-free survival. ${ }^{26}$

\section{Conclusion}

Patients who have demonstrated no evidence of disease progression following induction chemotherapy for NSCLC are candidates for maintenance therapy. At the present time, there is no blanket recommendation for maintenance treatment in patients with advanced NSCLC. Treatment recommendations should be individualized by the treating physician, with careful consideration of patient performance status and patient preference. Patients need to be made aware that while the toxicities reported in the maintenance arm of the trials were acceptable, chemotherapy holidays provide them with an interval free of treatment-related adverse effects. The current evidence from randomized Phase III trials shows a modest benefit to maintenance therapy, particularly in terms of progression-free survival. We feel that maintenance therapy should be considered in patients with a good performance status after a thorough discussion of the anticipated risks and the benefits with the individual patient and taking into account patient preference. If maintenance therapy is chosen, physicians should be aware that the most benefit has been shown with a switch maintenance approach.

\section{Disclosure}

The authors report no conflicts of interest in this work.

\section{References}

1. Jemal A, Siegel R, Jiaquan X, Ward E. Cancer Statistics, 2010. $C A$ Cancer J Clin. 2010;60(5):277-300.

2. Azzoli CG, Baker S Jr, Temin S, et al. American Society of Clinical Oncology Clinical Practice Guideline update on chemotherapy for stage IV non-small cell lung cancer. J Clin Oncol. 2009;27(36): 6251-6266.

3. Schiller JH, Harrington D, Belani CP, et al. Comparison of four chemotherapy regimens for advanced non-small-cell lung cancer. $N$ Engl J Med. 2002;346(2):92-98.

4. Ettinger DS, Akerley W, Bepler G, et al. Non-small cell lung cancer. J Natl Compr Canc Netw. 2010;8(7):740-801.

5. Stinchcombe TE, Socinski MA. Maintenance therapy in advanced nonsmall cell lung cancer: current status and future implications. JThorac Oncol. 2011;6(1):174-182.

6. Fidias P, Novello S. Strategies for prolonged therapy in patients with advanced non-small-cell lung cancer. J Clin Oncol. 2010;28(34): $5116-5123$.

7. Galetta D, Rossi A, Pisconti S, Millaku A, Colucci G. Maintenance or non-maintenance therapy in the treatment of advanced non-small cell lung cancer: that is the question. Cancer Treat Rev. 2010; 36(Suppl 3):S30-S33.

8. Soon YY, Stockler MR, Askie LM, Boyer MJ. Duration of chemotherapy for advanced non-small-cell lung cancer: a systematic review and meta-analysis of randomized trials. J Clin Oncol. 2009;27(20): 3277-3283.

9. Patel JD, Hensing TA, Rademaker A, et al. Phase II study of pemetrexed and carboplatin plus bevacizumab with maintenance pemetrexed and bevacizumab as first-line therapy for nonsquamous non-small-cell lung cancer. J Clin Oncol. 2009;27(20):3284-3289.

10. Brodowicz T, Krzakowski M, Zwitter M, et al. Cisplatin and gemcitabine first-line chemotherapy followed by maintenance gemcitabine or best supportive care in advanced non-small cell lung cancer: a phase III trial. Lung Cancer. 2006;52(2):155-163.

11. Perol M, Chouaid C, Milleron BJ, et al. Maintenance with either gemcitabine or erlotinib versus observation with predefined secondline treatment after cisplatin-gemcitabine induction chemotherapy in advanced NSCLC: IFCT-GFPC 0502 phase III study. J Clin Oncol. 2010;28(Suppl 15):Abstr 7507.

12. Belani CP, Waterhouse DM, Ghazal H, et al. Phase III study of maintenance gemcitabine (G) and best supportive care (BSC) versus BSC, following standard combination therapy with gemcitabine-carboplatin (G-Cb) for patients with advanced non-small cell lung cancer (NSCLC). J Clin Oncol. 2010;28(15 Suppl):Abstr 7506.

13. Belani CP, Barstis J, Perry MC, et al. Multicenter, randomized trial for stage IIIB or IV non-small-cell lung cancer using weekly paclitaxel and carboplatin followed by maintenance weekly paclitaxel or observation. J Clin Oncol. 2003;21(15):2933-2939.

14. Brabender J, Danenberg KD, Metzger R, et al. Epidermal growth factor receptor and HER2-neu mRNA expression in non-small cell lung cancer is correlated with survival. Clin Cancer Res. 2001;7(7):1850-1855. 
15. Hirsch FR, Varella-Garcia M, Bunn PA Jr, et al. Epidermal growth factor receptor in non-small-cell lung carcinomas: correlation between gene copy number and protein expression and impact on prognosis. J Clin Oncol. 2003;21(20):3798-3807.

16. Pirker R, Pereira JR, Szczesna A, et al. Cetuximab plus chemotherapy in patients with advanced non-small-cell lung cancer (FLEX): an openlabel randomized phase III trial. Lancet. 2009;373(9674):1525-1531.

17. Lynch TJ, Patel T, Dreisbach L, et al. Cetuximab and first-line taxane/ carboplatin chemotherapy in advanced non-small-cell lung cancer: results of the randomized multicenter phase III trial BMS099. J Clin Oncol. 2010;28(6):911-917

18. Herbst RS, Prager D, Hermann R, et al. TRIBUTE: a phase III trial of erlotinib hydrochloride (OSI-774) combined with carboplatin and paclitaxel chemotherapy in advanced non-small-cell lung cancer. J Clin Oncol. 2005;23(25):5892-5899.

19. Gatzemeier U, Pluzanska A, Szczesna A, et al. Phase III study of erlotinib in combination with cisplatin and gemcitabine in advanced non-small-cell lung cancer: the Tarceva Lung Cancer Investigation Trial. J Clin Oncol. 2007;25(12):1545-1552.

20. Giaccone G, Herbst RS, Manegold C, et al. Gefitinib in combination with gemcitabine and cisplatin in advanced non-small-cell lung cancer: a phase III trial - INTACT 1. J Clin Oncol. 2004;22(5):777-784.

21. Herbst RS, Giaccone G, Schiller JH, et al. Gefitinib in combination with paclitaxel and carboplatin in advanced non-small-cell lung cancer: a phase III trial - INTACT 2. J Clin Oncol. 2004;22(5):785-794.

22. Sandler A, Gray R, Perry MC, et al. Paclitaxel-carboplatin alone or with bevacizumab for non-small-cell lung cancer. NEJM. 2006;255(24): 2542-2550.

23. Reck M, von Pawel J, Zatloukal P, et al. Phase III trial of cisplatin plus gemcitabine with either placebo or bevacizumab as first-line therapy for nonsquamous non-small-cell lung cancer: AVAiL. J Clin Oncol. 2009;27(8):1227-1234.

24. Reck M, von Pawel J, Zatloukal P, et al. Overall survival with cisplatingemcitabine and bevacizumab or placebo as first-line therapy for nonsquamous non-small-cell lung cancer: results from a randomized phase III trial (AVAiL). Ann Oncol. 2010;21(9):1804-1809.

25. Westeel V, Quoix E, Moro-Sibilot D, et al. Randomized study of maintenance vinorelbine in responders with advanced non-small-cell lung cancer. J Natl Cancer Inst. 2005;97(7):499-506.

26. Fidias PM, Dakhil SR, Lyss AP, et al. Phase III study of immediate compared with delayed docetaxel after front-line therapy with gemcitabine plus carboplatin in advanced non-small-cell lung cancer. J Clin Oncol. 2009;27(4):591-598.

27. Ciuleanu T, Brodowicz T, Zielinski C, et al. Maintenance pemetrexed plus best supportive care versus placebo plus best supportive care for non-small-cell lung cancer: a randomised, double-blind, phase 3 study. Lancet. 2009;374(9699):1432-1440.

28. Takeda K, Hida H, Sato T, et al. Randomized phase III trial of platinumdoublet chemotherapy followed by gefitinib compared with continued platinum-doublet chemotherapy in Japanese patients with advanced non-small cell lung cancer: results of a West Japan Thoracic Oncology Group Trial (WJTOG0203). J Clin Oncol. 2010;28(5):753-760.
29. Gaafar RM, Surmont V, Scagliotti G, et al. A double-bind, randomized, placebo-controlled phase III study of gefitinib $(\mathrm{G})$ in patients (pts) with advanced NSCLC, non-progressing after first-line platinum-based chemotherapy (EORTC 08021-ILCP 01/03). J Clin Oncol. 2010;28 (15 Suppl):Abstr 7518.

30. Kelly K, Chansky K, Gaspar LE, et al. Phase III trial of maintenance gefitinib or placebo after concurrent chemoradiotherapy and docetaxel consolidation in inoperable stage III non-small-cell lung cancer: SWOG S0023. J Clin Oncol. 2008;26(15):2450-2456.

31. Thatcher N, Chang A, Parikh P, et al. Gefitinib plus best supportive care in previously treated patients with refractory advanced non-small-cell lung cancer: results from a randomised, placebo-controlled, multicentre study (Iressa Survival Evaluation in Lung Cancer). Lancet. 2005; 366(9496):1527-1537.

32. Cappuzzo F, Ciuleanu T, Stelmakh L, et al. Erlotinib as maintenance treatment in advanced non-small-cell lung cancer: a multicentre, randomised, placebo-controlled phase 3 study. Lancet. 2010;11(6): 521-529.

33. Kabbinanvar FF, Miller VA, Johnson BE, et al. Overall survival (OS) in ATLAS, a phase IIIb trial comparing bevacizumab (B) therapy with or without erlotinib (E) after completion of chemotherapy (chemo) with B for first-line treatment of locally advanced, recurrent, or metastatic non-small cell lung cancer (NSCLC). J Clin Oncol. 2010:28(Suppl 15): Abstr 7526.

34. Klein R, Wielage R, Muehlenbein C, et al. Cost-effectiveness of pemetrexed as first-line maintenance therapy for advanced nonsquamous non-small cell lung cancer. J Thorac Oncol. 2010;5(8):1263-1272.

35. Joerger M, Matter-Walstra K, Fruh M, et al. Addition of cetuximab to first-line chemotherapy in patients with advanced non-small-cell lung cancer: A cost-utility analysis. Ann Oncol. 2011;22(3)567-574.

36. Pao W, Miller V, Zakowski M, et al. EGF receptor gene mutations are common in lung cancers from "never smokers" and are associated with sensitivity of tumors to gefitinib and erlotinib. Proc Natl Acad Sci US A. 2004;101(36):13306-13311.

37. Lynch TJ, Bell DW, Sordella R, et al. Activating mutations in the epidermal growth factor receptor underlying responsiveness of non-small-cell lung cancer to gefitinib. N Engl J Med. 2004;350(21):2129-2139.

38. Yang CH, Yu CJ, Shih JY, et al. Specific EGFR mutations predict treatment outcome of stage IIIB/IV patients with chemotherapy-naïve non-small-cell lung cancer receiving first-line gefitinib monotherapy. J Clin Oncol. 2008;26(16):2745-2753.

39. Paez JG, Janne PA, Lee JC, et al. EGFR mutations in lung cancer: correlation with clinical response to gefitinib therapy. Science. 2004 304(5676):1497-1500.

40. Mok TS, Wu Y, Thongprasert S. Gefitinib or carboplatin-paclitaxel in pulmonary adenocarcinoma. $N$ Engl J Med. 2009;361(10):947-957.
Lung Cancer: Targets and Therapy

\section{Publish your work in this journal}

Lung Cancer: Targets and Therapy is an international, peer-reviewed, open access journal focusing on lung cancer research, identification of therapeutic targets and the optimal use of preventative and integrated treatment interventions to achieve improved outcomes, enhanced survival and quality of life for the cancer patient. Specific topics covered in the journal include:

\section{Dovepress}

Epidemiology, detection and screening; Cellular research and biomarkers; Identification of biotargets and agents with novel mechanisms of action; Optimal clinical use of existing anticancer agents, including combination therapies; Radiation and surgery; Palliative care; Patient adherence, quality of life, satisfaction; Health economic evaluations. 